\title{
Comparison of Mainstream Smoke Composition from CR20 Resin Filter and Empty-Cavity Filter Cigarettes by Headspace SPME Coupled with GCXGC TOFMS and Chemometric Analysis *
}

\author{
by \\ Michat Brokl ${ }^{1}$, Valle Morales ${ }^{1}$, Louise Bishop ${ }^{1}$, Christopher G. Wright ${ }^{1}$, Chuan Liu ${ }^{1}$, Jean-François Focant ${ }^{2}$, James \\ Nicol $^{3}$, Kevin G. McAdam ${ }^{4}$ \\ ${ }^{1}$ Group Research and Development, British American Tobacco, Regents Park Road, Southampton SO15 8TL, UK \\ ${ }^{2}$ CART - Chemistry Department, Organic \& Biological Analytical Chemistry, University of Liège, Liège, Belgium \\ ${ }^{3}$ JTN Consulting Limited, 272 Bath Street, Glasgow, Scotland, G2 4JR, UK \\ ${ }^{4}$ McAdam Scientific Ltd., 50 Leigh Rd, Eastleigh, SO50 9DT, UK
}

\section{SUMMARY}

A previously established method based on headspace solidphase microextraction (HS-SPME) and comprehensive two-dimensional gas chromatography $(\mathrm{GC} \times \mathrm{GC})$ coupled to time-of-flight mass spectrometry (TOFMS) has been used to evaluate and compare the profiles of semi-volatile compounds present in mainstream tobacco smoke particulate matter trapped on glass fibre filters for two types of cigarettes differing only in filter design. In the first cigarette, the filter cavity contained approximately $60 \mathrm{mg}$ of a weakly basic macroporous polystyrene resin cross-linked with divinyl benzene and with surface amine functionality (CR20), whereas in the second cigarette, it was empty.

Relative quantitative analysis, chemical identification, and chemical grouping allowed the use of both parametric and non-parametric analyses to identify differences in the chemical composition of the smokes from these cigarettes. The analysis demonstrated that in addition to the selective partial removal of volatile carbonyls and HCN demonstrated previously, CR20 selectively, but incompletely removed 316 compounds from the particulate phase of cigarette smoke, mainly aryl and aromatic hydrocarbons as well as other more volatile species. In contrast, the relative proportion of amines, hydroxylated aromatic compounds and less volatile species was increased in the smoke from the cigarette containing CR20 in the filter.

Our findings show that high resolution GC techniques combined with mass spectrometry and chemometric approaches are powerful tools for deconvoluting the complexity of combustion aerosols, as well as helping to identify changes in chemical composition resulting from modifications to cigarette designs. [Beitr. Tabakforsch. Int. 28 (2019) 231-249]

\section{KEYWORDS}

Solid-phase microextraction (SPME); Comprehensive twodimensional gas chromatography $(\mathrm{GC} \times \mathrm{GC})$; Mainstream tobacco smoke particulate phase (PP); Fisher ratio; Chemometric analysis

\section{ZUSAMMENFASSUNG}

Es wurde eine zuvor entwickelte Methode beruhend auf der Headspace-Festphasenmikroextraktion(HS-SPME) und der umfassenden zweidimensionalen Gaschromatographie $(\mathrm{GC} \times \mathrm{GC})$ gekoppelt mit der Flugzeit-Massenspektrometrie (TOFMS) eingesetzt, um die Profile schwerflüchtiger Verbindungen in auf Glasfaserfiltern gesammelten Par- 
tikeln des Hauptstromrauchs von zwei Arten Zigaretten, die sich nur im Filterdesign unterschieden, zu evaluieren und vergleichen. Bei der ersten Zigarette enthielt der Filterhohlraum ca. $60 \mathrm{mg}$ eines schwach basischen makroporösen Polystyrolharzes vernetzt mit Divinylbenzol und war ausgestattet mit einer Aminfunktion der Oberfläche (CR20), bei der zweiten Zigarette war er hingegen leer.

Die relative quantitative Analyse, chemische Identifizierung und chemische Gruppierung ermöglichten den Einsatz sowohl der parametrischen als auch der nicht-parametrischen Analyse zur Feststellung der Unterschiede in der chemischen Zusammensetzung des Rauchs bei beiden Zigaretten. Die Analyse ergab, dass zusätzlich zur zuvor nachgewiesenen selektiven partiellen Entfernung von flüchtigen Carbonylen und Cyanwasserstoff (HCN), die Aminfunktion CR20 selektiv, aber unvollständig 316 Verbindungen aus der partikulären Phase des Zigarettenrauchs entfernte, und zwar hauptsächlich aromatische und Aryl-Kohlenwasserstoffe sowie andere stärker flüchtige Spezies. Demgegenüber war der relative Anteil von Aminen, hydroxylierten aromatischen Verbindungen und weniger flüchtigen Spezies im Rauch der Zigarette mit CR20-Funktion im Filter erhöht.

Unsere Ergebnisse zeigen, dass hochauflösende Gaschromatographietechniken in Kombination mit Massenspektrometrie sowie chemometrischen Ansätzen leistungsfähige Instrumente zur Dekonvolution der Komplexität von Verbrennungsaerosolen sind und zudem dazu beitragen können, durch Modifikationen des Zigarettendesigns bedingte Veränderungen der chemischen Zusammensetzung zu erkennen. [Beitr. Tabakforsch. Int. 28 (2019) 231-249]

\section{RESUME}

Une méthode précédemment mise au point et fondée sur une micro-extraction sur phase solide dans l'espace de tête (HS-SPME) et sur une chromatographie en phase gazeuse bidimensionnelle $(\mathrm{GC} \times \mathrm{GC})$ couplée à une spectrométrie de masse à temps de vol (TOFMS) fut utilisée dans le but d'évaluer et de mettre en regard les profils des composés semi-volatiles présents dans les particules de fumée principale de tabac piégées par les filtres en fibre de verre de deux types de cigarettes se différenciant uniquement par la conception distincte de leur filtre. Dans le cas de la première cigarette, la cavité du filtre contenait environ $60 \mathrm{mg}$ d'une résine de polystyrène macroporeuse de faible basicité, croisée au divinylbenzène et présentant une fonction amine de surface (CR20); tandis que la cavité du filtre de la seconde cigarette était vide.

Une analyse quantitative relative, une identification chimique ainsi qu'un regroupement chimique permirent le recours à des analyses à la fois paramétriques et nonparamétriques afin d'identifier les différences de composition chimique des fumées de ces cigarettes. L'analyse apporta la preuve qu'en plus du retrait partiel sélectif des carbonyles volatiles et de l'acide cyanhydrique attesté précédemment, la fonction CR20 permettait, de façon sélective mais incomplète, l'élimination de 316 composés de la phase particulaire de la fumée de cigarette, à savoir principalement les hydrocarbures aryles et aromatiques ainsi que d'autres substances plus volatiles. En revanche, la proportion relative des amines, des composés aromatiques hydroxylés et des substances moins volatiles était en augmentation dans la fumée de la cigarette contenant la CR20 dans son filtre.

Nos observations démontrent que des techniques de chromatographie en phase gazeuse à haute résolution combinées à la spectrométrie de masse et à la chimiométrie constituent des outils performants de déconvolution de la complexité des aérosols issus de la combustion et contribuent également à l'identification des modifications de la composition chimique résultant des changements apportés à la conception des cigarettes. [Beitr. Tabakforsch. Int. 28 (2019) 231-249]

\section{INTRODUCTION}

Tobacco smoke is an aerosol containing an extremely complex mixture of chemicals. It comprises liquid and/or solid droplets, termed the particulate phase (PP), suspended in a mixture of gases and volatiles, termed the gas and vapour phases (VP). Many semi-volatile compounds partition dynamically between both phases. Most recent estimates indicate that there are more than 6,000 identified compounds in tobacco smoke, and most of these are contained in the particulate phase (1). The chemical mixture comprising cigarette smoke has been classified as a human carcinogen $(2,3)$, and many of the individual semi-volatile organic compounds (SVOCs) present in whole smoke, such as benzene, ethylbenzene, and styrene, are also known or potential human carcinogens. In a toxicological risk assessment, the gas and vapour phase constituents of tobacco smoke were found to dominate the cancer risk index (4).

As a result, many attempts have been made to selectively reduce toxicants in cigarette smoke (5). Because smokingrelated diseases are dose-dependent, the "Committee to Assess the Science Base for Tobacco Harm Reduction" of the Institute of Medicine concluded that "... for many diseases attributable to tobacco use, reducing risk of disease by reducing exposure to tobacco toxicants is feasible" (6).

Various filter components have been tested for their ability to selectively remove toxicants from tobacco smoke. An increasing number of cigarettes contain porous adsorbents, such as activated carbon (AC), which can remove a broad range of VOCs from smoke via adsorption or physisorption (7-9). Chemisorption, in which filter materials possess active surface chemical reactivity, is also a viable mechanism for the selective filtration of volatile components (10-13). BRANTON et al. recently showed that chemisorption is effective for the removal of certain vapour phase toxicants from cigarette smoke. They tested a macroporous, polystyrene based ion-exchange resin (Diaion ${ }^{\mathbb{B}} \mathrm{CR} 20$, Mitsubishi Chemical Corporation, Tokyo, Japan; hereafter CR20) with surface amine group functionality as a filter component that might react with volatile compounds such as aldehydes and HCN in mainstream cigarette smoke (13). Characterisation of CR20 revealed a small surface area but extensive surface chemistry, in contrast to coconut-derived AC, which has extensive porosity (8). The surface functional groups of the resin beads were characterized by 
TOFMS, which showed the presence of distinctive aromatic signals, surface nitrogen (as $\mathrm{CN}^{-}$ions), organonitrogen groups (e.g., $[\mathrm{OCN}]^{-}$fragment, indicative of amide/amide-like functionalities; and $\mathrm{C}_{\mathrm{x}} \mathrm{H}_{\mathrm{y}} \mathrm{N}^{+}$signals, indicative of amine/amine-like groups and ammonium-type species). Thus, CR20 has structural characteristics indicating weak physisorption properties, but sufficient surface functionalities to selectively remove aldehydes and HCN from cigarette smoke. The reductions of aldehydes and $\mathrm{HCN}$ were greater than those achieved using AC. 2-Butanone was removed with increasing efficiency by increasing amounts of CR20 in the filter, suggesting a low level of chemisorption by CR20 for this ketone, although the removal of another ketone, acetone, was poor (13).

The vapour phase analysis of CR20 filters presented by BRANTON et al. provided a relatively narrow examination of changes in smoke chemistry between CR20 and cellulose acetate filtered cigarettes (13). As the chemical composition of smoke from the CR20-filtered cigarette is different to a standard cellulose acetate filtered cigarette, it was decided to investigate more fully the associated chemical differences in smoke chemistry. To monitor wider changes in cigarette smoke composition, a comprehensive analytical approach is needed; however, the complexity, number and concentration range of compounds in particulate phase samples means that an exhaustive analysis is very difficult. As a result, many studies have focused on individual classes of compounds present in tobacco smoke via one-dimensional gas chromatography (1DGC) coupled with time-of-flight mass spectrometry (TOFMS), including several studies on VOCs (14-17).

In the past 20 years, comprehensive two-dimensional GC $(\mathrm{GC} \times \mathrm{GC})$, in which consecutive separations are performed on two orthogonal column phases (e.g., 18), has been applied to the analysis of more complex solutions, including food extracts (19) and various fractions of tobacco smoke (20-23). The increased separation capacity of $\mathrm{GC} \times \mathrm{GC}-\mathrm{TOFMS}$, due to consecutive separations, higherdimensional structure-retention relationships, peak compression and improved signal-to-noise ratio $(\mathrm{S} / \mathrm{N})$, provide much greater peak capacity and chromatographic selectivity than one-dimensional GC. $\mathrm{GC} \times \mathrm{GC}$ can avoid the need for time-consuming sample preparation procedures via analyte and/or matrix pre-separation (19); however, processing the relatively large volumes of data obtained using non-targeted comprehensive screening can be very timeconsuming.

Most recently, GC $\times \mathrm{GC}$-TOFMS has been used for the analysis of the mainstream tobacco smoke particulate phase using liquid extraction and dynamic headspace (DHS) sampling $(24,25)$. In this study, automated peak finding and mass spectral deconvolution combined with scripting and manual revision of library hits were used to evaluate library search results. In a comparison between solvent extraction and DHS sampling of the smoke particulate phase, the revised peak table contained nearly 1800 and over 900 individual compounds, respectively (24). The two extraction methods were shown to be complementary, leading to only $11 \%$ of repeated analytes, and their combination gave rise to a list of almost 2500 individual smoke constituents. In addition, the number of compounds detected in each chemical class was significantly higher in the
DHS sampling than in the methanol extraction. Thus, DHS sampling might provide a more comprehensive analytic approach for semi-volatile compounds.

Solid-phase microextraction (SPME) - a rapid solvent-free and sensitive method of extraction based on the sorption of analytes present in a sample or its headspace by a thin film of an extracting phase immobilized over the surface of a fused-silica fibre (26) - has also been used to assess various classes of compounds in cigarette smoke $(16,17,27-35)$. In a recent study, headspace SPME GC $\times$ GC-TOFMS was optimized via a multivariate response surface strategy for the evaluation of multiple VOCs in mainstream tobacco smoke particulate matter (25). The optimized protocol was used in the analysis of two types of cigarette: one with active charcoal (AC) in the filter, and one with standard cellulose acetate (CA) in the filter. Principal component analysis (PCA) allowed clear differentiation of the two cigarette types, while Fisher ratio analysis (36) allowed identification of compounds responsible for the chemical differences between the cigarette samples. Of 143 compounds, 134 analytes were reduced by the active carbon filter, while for 9, the classical cellulose acetate filter was more efficient.

Building on our previous study in which a filter containing CR20 resin was shown to efficiently remove aldehydes and HCN (13), here we have applied the optimised headspace SPME-GC $\times$ GC-TOFMS approach (25) to evaluate whether this CR20 resin can substantially reduce multiple semivolatile compounds in the cigarette smoke particulate phase. Mainstream smoke from a cigarette incorporating a three-segment filter comprising $10 \mathrm{~mm}$ of CA at the tobacco rod end, a 4-mm cavity section filled with approximately $60 \mathrm{mg}$ of CR20, and a 13-mm CA section at the mouth end, was compared against smoke from a second cigarette with identical tobacco blend, paper, and dimensions but an empty filter cavity (Figure 1).

\section{MATERIALS AND METHODS}

\section{CR20}

The filter material used in this study, CR20, is a polystyrene based material cross-linked with divinyl benzene, with surface (primary) amine group functionality, and whose filtration characteristics have been characterised extensively (13). The material was prepared using a modified synthesis process, designed to provide a lower odour material (CR20L), and was used in this study in the form of $600-\mu \mathrm{m}$ diameter beads, $15 \%$ moisture content and $0.92 \mathrm{meq} / \mathrm{cm}^{3}$ total exchange capacity. It possesses a predominantly macroporous structure with some large mesopores, a BET surface area of $44 \mathrm{~m}^{2} \mathrm{~g}^{-1}$ and a pore volume (at a relative pressure, $\mathrm{P} / \mathrm{P}_{0}$, of 0.95 ) of $0.08 \mathrm{~cm}^{3} \mathrm{~g}^{-1}$; it possesses a broad pore size distribution of 25-900 nm centred at $105 \mathrm{~nm}$ with a volume of $1.0 \mathrm{~cm}^{3} \mathrm{~g}^{-1}$ and a bulk density of $0.50 \mathrm{~g} \mathrm{~cm}^{-3}$. These properties were consistent with very weak physisorption properties. The resin particle surfaces showed the presence of distinctive aromatic signals, surface nitrogen (as $\mathrm{CN}^{-}$ions), organo-nitrogen groups, (e.g. [OCN $]^{-}$fragment, indicative of amide/amidelike functionalities) and $\mathrm{C}_{\mathrm{x}} \mathrm{H}_{\mathrm{y}} \mathrm{N}^{+}$signals, indicative of 

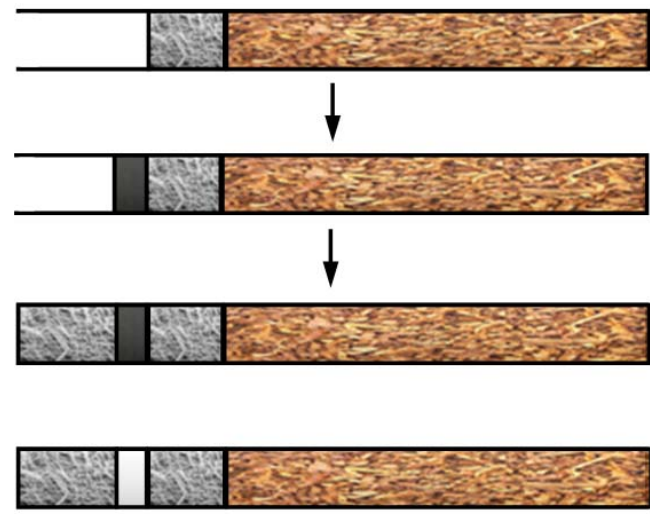

Step 1: Recessed filtered cigarette (open

ended filter). Mouth-end is on the left

Step 2: Addition of CR2O beads

Step 3: CR20 held in place by cellulose

acetate plug (CR20 Test Cigarette - "CR20")

Empty cavity control cigarette - "EC"

\section{Tobacco Rod}

\section{Cellulose Acetate}

\section{CR20}

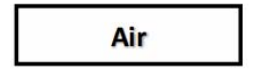

Figure 1. Construction of CR20 and EC cigarettes.

amine/amine-like groups and ammonium-type species. It had a maximum basicity of $1.02 \mathrm{mmol} \mathrm{g}^{-1}$ and was more hydrophobic than activated charcoal. These properties were sufficient to display significant chemisorption towards vapour phase aldehydes and $\mathrm{HCN}$ (13).

\section{Cigarettes}

Two types of cigarettes differing only in filter design were examined in this study (Figure 1). A 27-mm length, threesegment filter comprising a 10 -mm cellulose acetate section at the tobacco rod end, a 4-mm cavity section, and a 13-mm cellulose acetate section at the mouth end was used. In cigarettes coded CR20, the cavity was filled with $60 \pm 1 \mathrm{mg}$ of CR20 resin (a weakly basic macroporous polystyrene resin cross-linked by divinyl benzene, with surface amine functionality), while in cigarettes coded EC the 4-mm cavity was left empty. In both cases the cellulose acetate base-material was plasticised with $7 \%$ triacetin. Cigarettes CR20 and EC had a circumference of $24.6 \mathrm{~mm}$ and were made up of a 56-mm long tobacco rod containing a Virginia style tobacco blend (tobacco rod density of $255 \mathrm{mg} \mathrm{cm}^{-3}$ at a moisture content of 13\%). The research cigarettes were provided by British American Tobacco (Southampton, UK).

\section{Smoking conditions}

Smoke samples were produced using a Borgwaldt RM20 rotary smoking machine (Borgwaldt KC, Inc., Richmond, VA, USA). Smoking was conducted according to the relevant ISO standards applying a $35-\mathrm{mL}$ puff of $2 \mathrm{~s}$ duration taken every $60 \mathrm{~s}$ with no blocking of filter ventilation holes (37). Cigarettes were lit using an electric lighter (Borgwaldt KC Inc., Richmond, VA, USA).

\section{Samples}

Cigarettes and Cambridge filter pads were conditioned for at least $48 \mathrm{~h}$ at $60 \%$ relative air humidity and $22^{\circ} \mathrm{C}$ prior to analysis (38). After conditioning, for each analysis, five conditioned cigarettes were smoked and the particulate phase of mainstream smoke (PP) was collected on a Cambridge filter pad (CFP). Smoking was conducted four times for each cigarette, each run producing a separate CFP sample ("Procedural Replicates"). After smoking, the filter pad was cut into quarters and each quarter was placed in a separate $20-\mathrm{mL}$ headspace vial which was sealed and analysed immediately after. Analysis of each both cigarette types therefore each yielded four sample replicates, i.e., Cambridge filter pads containing particulate phase material. The four quarter filters from each CFP constituted technical replicates.

\section{GC analysis}

Each sample was analysed by SPME GC $\times$ GC TOFMS generating 32 chromatograms in total; 16 each for the CR20 and EC prototype cigarettes, each comprising four replicates, each replicate having four repeats. The instrument used was a LECO Pegasus4D (Saint Joseph, MI, USA) equipped with a dual jet modulator and a secondary column oven.

\section{HS-SPME procedures}

Headspace SPME extraction conditions were optimized in our previous study (25). The polyacrylate fibre (PA) fibre was conditioned prior to use according to manufacturer's instructions in a Gerstel (Kortrijk, Belgium) fibre bake out station. An $85-\mu \mathrm{m}$ Polyacrylate SPME fibre (Sigma Aldrich, Overijse, Belgium) was exposed to the sample headspace for $10 \mathrm{~min}$ at $40^{\circ} \mathrm{C}$ after a 10 -min sample incubation period at $50{ }^{\circ} \mathrm{C}$. The fibre was desorbed in a CIS4 Cooled Injection System (Gerstel, Kortrijk, Belgium) using the following temperature program: isothermal period at $-20{ }^{\circ} \mathrm{C}$ for $0.5 \mathrm{~min}$, a ramp of $12^{\circ} \mathrm{C} \mathrm{s}^{-1}$ to $250^{\circ} \mathrm{C}$ and held at $250{ }^{\circ} \mathrm{C}$ for $2 \mathrm{~min}$. After desorption the fibre was reconditioned for $40 \mathrm{~min}$ at $275^{\circ} \mathrm{C}$ to eliminate possible carry-over. 20 -mL headspace vials, polytetrafluoroethylene-faced (PTFE) septa magnetic crimp caps, and an automated SPME holder were obtained from Gerstel (Kortrijk, Belgium). 


\section{$G C \times G C$ setup and analytical conditions}

The first dimension $\left({ }^{1} \mathrm{D}\right)$ column was a low-polarity $5 \%$ phenyl polysilphenylene-siloxane phase (BPX5; $30 \mathrm{~m} \times 0.25 \mathrm{~mm}$ i.d. $\times 0.25 \mu \mathrm{m}$ film thickness; SGE International, Victoria, Australia) connected by means of a SilTite ${ }^{\mathrm{TM}} \mu$-Union (SGE International, Victoria, Australia) to a second dimension $\left({ }^{2} \mathrm{D}\right)$ midpolarity Crossbonded ${ }^{\circledR}$ silarylene phase column exhibiting similar selectivity to $50 \%$ phenyl $/ 50 \%$ dimethyl polysiloxane $\left(\mathrm{Rxi}^{\circledR}-17 \mathrm{Sil} \mathrm{MS} ; 1.0 \mathrm{~m} \times 0.15 \mathrm{~mm}\right.$ i.d. $\times 0.15 \mu \mathrm{m}$ film thickness; Restek Corp., Bellefonte, PA, USA). The ${ }^{2} \mathrm{D}$ column was installed in a separate oven located inside the main GC oven, providing more flexible temperature control. The system was equipped with a Gerstel MultiPurpose Sampler (MPS 2XL), SPME option for procedural automation, and the CIS4 Cooled Injection System. The carrier gas was helium at a corrected constant

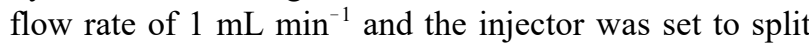
mode with split ratio of $1: 15$.

The main oven temperature program comprised an isothermal period at $50{ }^{\circ} \mathrm{C}$ for $3 \mathrm{~min}$, a ramp of $4{ }^{\circ} \mathrm{C} \min ^{-1}$ to $220^{\circ} \mathrm{C}$ followed by a ramp of $20^{\circ} \mathrm{C} \mathrm{min}^{-1}$ to $300{ }^{\circ} \mathrm{C}$ and a final isothermal period at $300{ }^{\circ} \mathrm{C}$ for $2.5 \mathrm{~min}$. The secondary oven was programmed with a $15{ }^{\circ} \mathrm{C}$ offset above the primary oven. The modulation parameters consisted of $2 \mathrm{~s}$ modulation period ( $400 \mathrm{~ms}$ hot pulse and $600 \mathrm{~ms}$ cold pulse time) and a temperature offset of $20^{\circ} \mathrm{C}$ above the secondary oven. Mass spectra were acquired in the range $\mathrm{m} / \mathrm{z}$ $45-400$ at the acquisition rate of 100 spectra $\sec ^{-1}$. The ion source temperature was set at $230^{\circ} \mathrm{C}$ and the transfer line temperature was set at $250{ }^{\circ} \mathrm{C}$. The detector voltage was $1500 \mathrm{~V}$ and the ionization electron energy (EI source) was set at $70 \mathrm{eV}$. Data were acquired using LECO Chro$\operatorname{maTOF}^{\circledR}$ software version 4.50 .

\section{Data processing}

Data processing for multivariate comparison of CR20 and EC cigarettes was performed using the pixel-based software package GC Image ${ }^{\mathrm{TM}}$ version $2.4 \mathrm{a} 3$ (Zoex Corporation, Houston, TX, USA). Image Investigator, part of the GC Image $^{\mathrm{TM}}$ software package, was used to analyze multiple chromatograms and examine statistical characteristics and trends.

Chromatograms from the 4 technical replicates of each of the 4 procedural replicates of the CR2 0 cigarette and the 4 technical replicates of each of the 4 procedural replicates of the EC cigarette (a total of 32 chromatograms) were submitted to Image Investigator. The chromatograms were pre-processed by means of background correction, blob detection, and phase shift, and then a cumulative chromatogram was created by aligning and combining all chromatograms into a single image. This image reflected all of the constituents that were present in all samples. Each peak present in this image was delineated, forming regions that were recorded and used to create a template. For each of the peaks, the template matrix recorded retention times in both dimensions $\left({ }^{1} t_{R}\right.$ and $\left.{ }^{2} t_{R}\right)$ and a rule expressed in Computer Language for Identifying Chemicals (CLIC) (39) that specifies both the reference mass spectrum in the template and the required mass spectral match factor that must be reached when in use. After manual cleaning for column bleed signals, artefacts associated with peak tailing and other system artefacts, a set of 836 regions was created in the template.

Each of the individual HS-SPME GC $\times$ GC-TOFMS chromatograms generated by the replicated analyses of both CR20 and EC cigarettes were mapped back to this template and each region defined a feature for each chromatogram. Library searching was carried out using NIST/EPA/NIH Mass Spectral Library (NIST 11) and Wiley Registry of Mass Spectral Data ( $9^{\text {th }}$ Edition). Linear retention indices (LRIs) for the first chromatographic dimension were calculated using alkanes present in a sample. Aroma Office ${ }^{2} \mathrm{D}$ (Gerstel, Tokyo, Japan) and its Linear Retention Indices (LRI) database of over 100,000 entries was used for the manual verification of compound identities when possible.

\section{Dataset preparation}

Processing and classification - the chromatography responses were normalised to give overall percentage response within each chromatogram, and thus to allow comparison between experiments. Normalisation adjusts for between-sample differences in total particulate matter and is a standard procedure in analytical methods in which overall sample dilution is not completely controlled.

Test for significance - the values for the 4 repeats within each replicate were averaged, and the averages were then compared using a two-sample t-test, with Welch's correction for unequal variances, and an alpha risk of 0.05 .

Ordinal classification - For each analyte the ratio of the mean \% response between the two series was calculated, to give a ratio of normalized signal intensity. Finally, ordinal classifications were assigned for each analyte based on these statistics (Table 1). The ordinal scale was coded so that increasing number corresponds to increasing analyte concentration in the particulate phase from the EC product in comparison to the level in the CR20.

Table 1. Criteria for assignment of ordinal classifications for each analyte.

\begin{tabular}{l|c|c}
\hline $\begin{array}{c}\text { Selectivity } \\
\text { (ordinal scale) }\end{array}$ & $\begin{array}{c}\text { Signal (EC) / } \\
\text { Signal (CR20) }\end{array}$ & $\begin{array}{c}\text { Significance } \\
\text { (t-test) }\end{array}$ \\
\hline 1 & $<1$ & yes \\
2 & any value & no \\
3 & $>1$ & yes \\
\hline
\end{tabular}

Interrogation of chemical structures - GC-MS provides chemical assignments via spectral library matching. Both automated look-up and manual intervention approaches were used to identify peaks. Peaks in which identification remained ambiguous after this stage were removed from the data (row-wise deletion). Once chemical identities were established it was possible to use cheminformatics to interrogate the chemical features. This allowed classification according to chemical functional groups, in order to sim- 
plify further analyses, and to gather data for compound physical parameters (e.g., vapour pressure) using calculated or archived values.

\section{Chemical group classification}

Cheminformatics techniques for unsupervised classification of chemicals are useful to support the assignment of compounds to discrete groups. Discrete groups are desirable for statistical analysis, because each compound can be given a single classifier that summarises its chemical functionality. This opens a path to using simple regression tools with easily interpretable results.

A common classification approach uses structural keys to produce fingerprints based on chemical maps of each molecule. These fingerprints are long check-lists of differentiating features, with a binary code to indicate if they are present in a molecule. They can be subjected to hierarchical clustering algorithms to split chemical sets into subgroups of similar molecules. A non-trivial step in dealing with tabulated chemical identifiers is to assign structures to the compound names provided. Peak identities were cross-checked with several identifiers, using web-based services, mostly mediated by the Webchem package in the $\mathrm{R}$ statistical programming environment. Data were collated into a single spreadsheet containing identities, SMILES representations (containing isomeric information where relevant), CAS numbers and the systematic IUPAC indexing term (InchiKey). The SMILES strings were used to obtain molecular weights, exact masses and water/octanol partition function estimates (xlogP) using the RCDK package in R.

Preliminary classification into chemical groups was performed using hierarchical clustering with the RCDK Package. This assigned each chemical with an 881 bit Pubchem structural fingerprint, suitable for building a distance matrix by the Tanimoto method (also called the Jaccard index).

Dissimilarity was assessed using the Ward method. A 15-group classification was chosen, based on visual inspection of the dendrogram. In most cases this was remarkably effective at drawing together chemically similar molecules, but there were a number of mis-matches. The assignments were manually adjusted to give a comprehensive 13-group system, which was further collapsed to give an intermediate-resolution 10-group classification, and further condensed to give a 7-group (coarse) classification system.

When adjusting classes, precedence was given to polar and reactive groups: for example, a carbonyl with an alcohol would be classified as carbonyl. The ranking for this was defined as: [unusual misc. groups/acid/amine] > carbonyl $>$ [ester/amide] $>$ alcohol $>$ ether $>$ hydrocarbon. In this manner, chemicals were classed together, according to reactive functional groups, and several polar, minority species were grouped together for simplicity.

\section{Statistical data interrogation methods to identify systematic differences between filter types}

Both parametric and non-parametric methods were used to examine the influence of chemical class, physical parameters, and filter selectivity on differences between the particulate phase compositions of smoke from the two cigarettes.
Non-parametric tests - analysis of chemical functionality

The Kruskal-Wallis test offered a robust method to examine differences in the ratio of analyte response across the chemical subgroups. This test compared median scores of subgroups (chemical grouping using the 10-group classification system); with z-scores to test the significance of the difference in median scores. Mood median test was also used to assess the equality of medians from the smoke constituent populations. The mean for each chemical group was assigned a confidence interval. Any interval that did not contain the overall grand median was regarded as significantly different from the other populations.

\section{- Parametric data modelling - analysis of physical and chemical molecular properties}

We explored statistical techniques that included terms for physical parameters, such as volatility. The first dimension retention time $\left({ }^{1} t_{R}\right)$ was used to represent decreasing volatility and the second dimension retention time $\left({ }^{2} t_{R}\right)$ to represent compound polarity. We also used the estimated water/octanol partition coefficient $(\mathrm{x} \log \mathrm{P})$ for each structure, as a proxy for lipophilicity. These continuous variables were used as covariates in the following models.

Linear discriminant analysis (LDA) - a generalization of Fisher's linear discriminant was used to identify linear combinations of features to distinguish between the smoke chemistry profiles from the two cigarettes.

Ordinal Logistic Regression - A more comprehensive model was obtained using the logit link function of ordinal logistic regression. Filtration selectivity was assigned as the response variable, with division into a 3 point ordinal scale as described previously. In this scale, a high number indicates a compound being depleted in the particulate phase of the CR2 0 product. The first dimension retention time was included as a covariate to represent (decreasing) volatility. The second dimension retention time represented (increasing) polarity. The chemical clusters (10-group classification) were each used as dichotomous variables. Model simplification was by stepwise removal of terms, assessed by inspection of $\mathrm{P}$ values and confidence intervals at each stage. Levels of agreement between observed and predicted classifications were described by Somers' D statistic and Kendall's tau-a parameter. The analysis was performed in Minitab.

Linear Regression - A general linear model was fitted for the ratio of the analyte intensities between product types, against retention times as continuous independent variables, with the inclusion of the 10-group chemical classification assignments as dichotomous factors. Two-way interactions were included, model simplification was by backwards removal of the least significant terms.

\section{RESULTS}

\section{Smoke composition from CR20 and EC cigarettes}

The GC oven profile has been described above. The region of interest has a constant temperature gradient. Samples eluted from column 1 between 3.6-39.2 $\mathrm{min}$ in this dimen- 

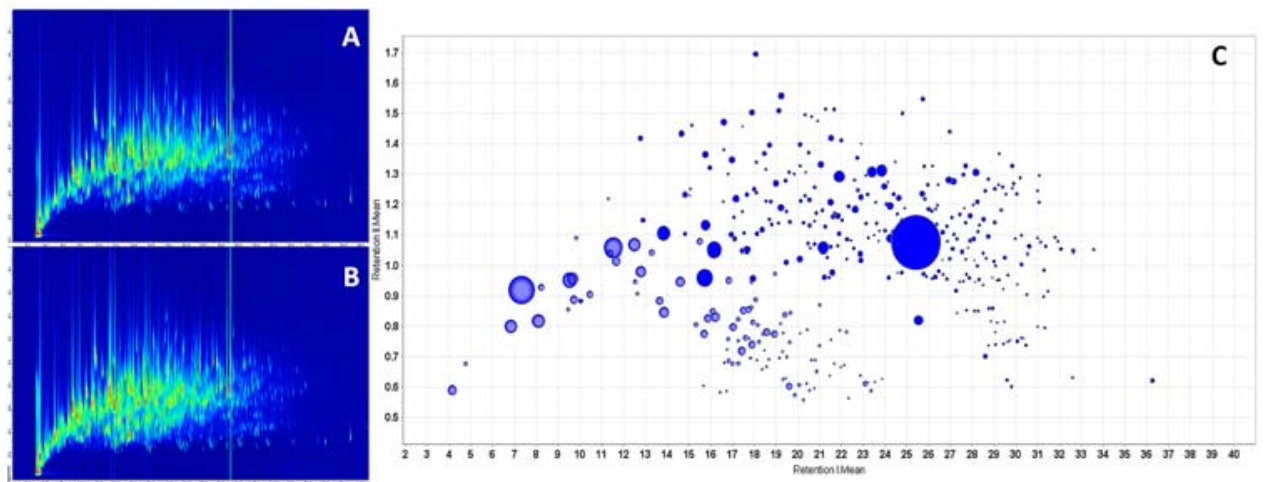

Figure 2. Comparison of the chromatograms from CR20 and EC cigarettes. $A$ is a chromatogram of CR20 smoke, $B$ is a chromatogram of EC smoke and $\mathrm{C}$ is a statistical comparison between the two: shaded blobs are compounds less abundant (reduced) in CR20 smoke.

sion. The $\mathrm{GC} \times \mathrm{GC}$ chromatograms from the $\mathrm{CR} 20$ cigarette and the EC cigarette are presented in Figure 2, and show the chemical complexity of the analysed smoke constituents in both cases. Retention times for column 1 were found to be reasonably normally distributed. The oven temperature can be considered isothermal for column 2 due to the modulation period of $2 \mathrm{~s}$. Consistent with this the retention times for column 2 were under $1.8 \mathrm{~s}$, but the peak retention time distribution for column 2 was less regular and was positively skewed (Appendix Figures Ala and b).

Interrogation of the chemical species in the database showed that the chemical names provided by the GC/MS libraries were generally clear, and could be interpreted. However, chemical nomenclature has inconsistencies between regions and disciplines, and it was a lengthy process to verify many names. Automated look-up services via API requests to databases provided reliable, crosschecked assignments for the majority, but approximately $25 \%$ required detailed work to verify assignments, and a number where the chemical assignment was undefined, ambiguous or implausible were removed from the data (18 rows). The deleted compounds comprised a small fraction of the overall data set. The resulting peak spreadsheet has 128 columns and 818 rows, and includes chemical drawings of all species. Full details are provided in Supplementary Information File (online), and an example of the database is provided in Table 2 (see next page).

The analytes signal intensities were approximately lognormally distributed, with similar profiles between products (Appendix, Figure A2). Empirical CDF plots also resembled lognormal profiles (Appendix, Figure A3). A marginal plot of the signal-to-noise ratio (SNR) for the two products showed that the primary analytical signals were generally equivalent across all peaks, prior to normalisation.

The normalised signal intensities for many chemicals were different between cigarette smoke samples, depending on which filter type was used. These differences are represented by plotting the ratio of the signal intensity between the two products, as a histogram in Figure 3. This showed three populations with approximately normal distributions

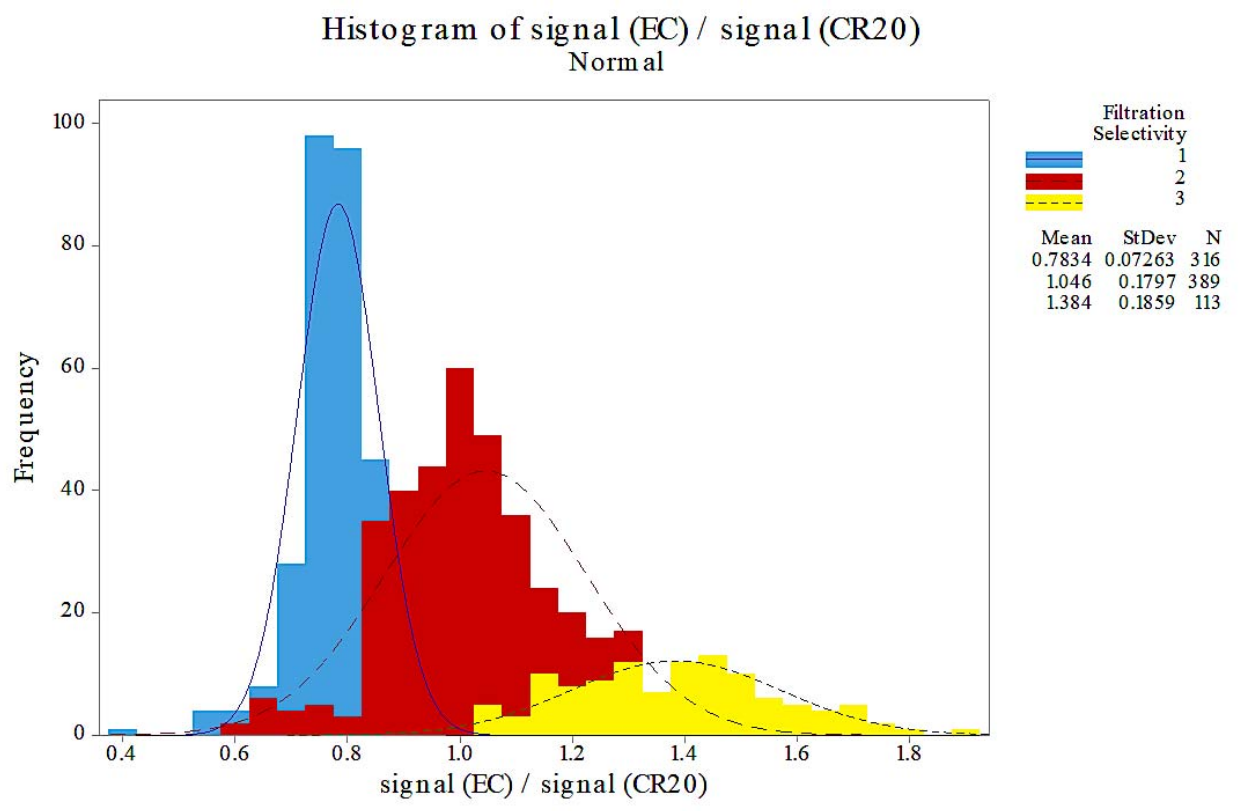

Figure 3. Histogram of normalized signal intensity ratios for compounds found in CR20 and EC cigarettes. 


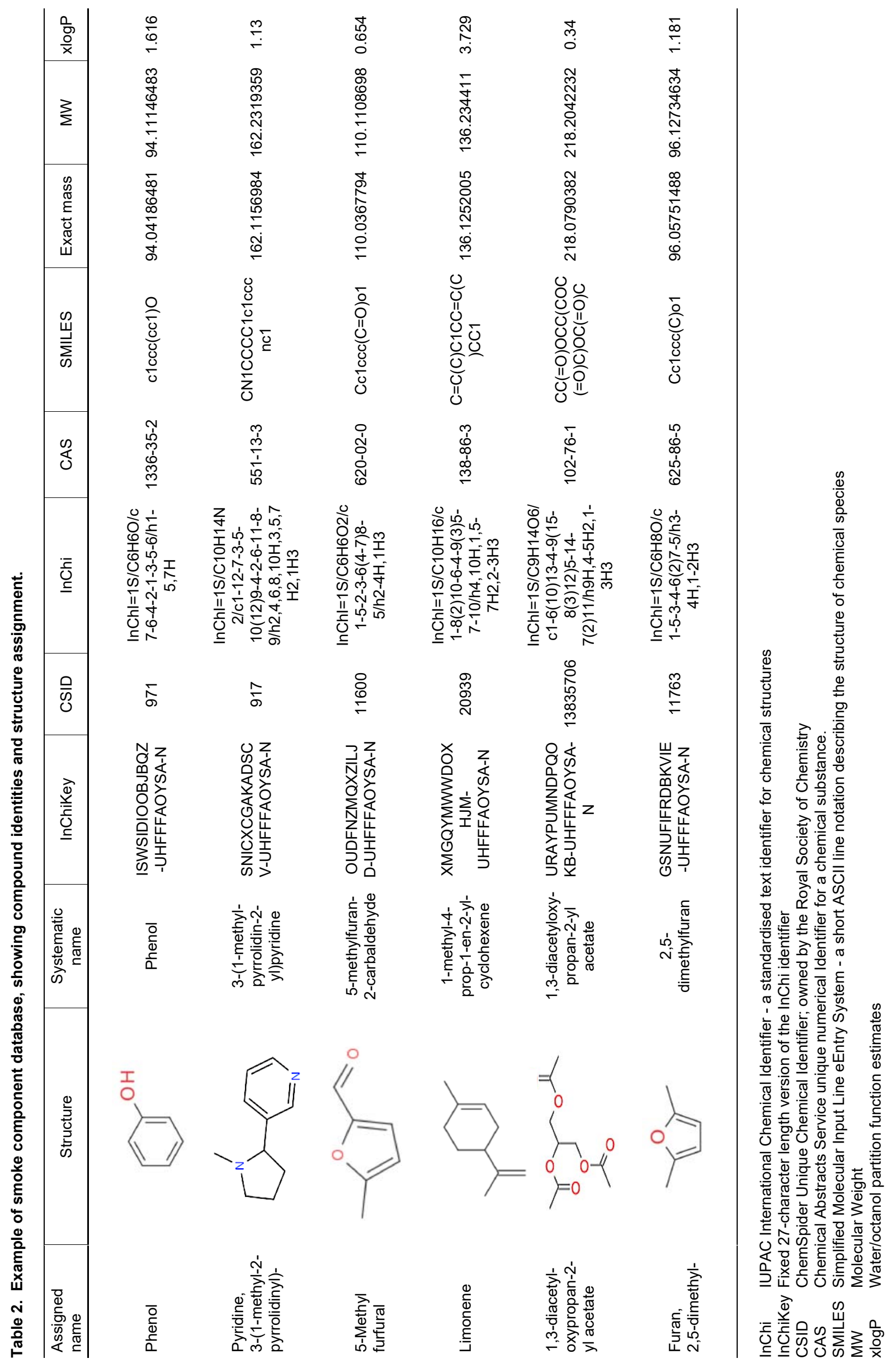


Table 3. 13-Group system.

\begin{tabular}{|c|c|c|}
\hline Chemical functionality present (13-group system) & Cluster number & Number of members \\
\hline $\begin{array}{l}\text { Mainly phenolic, some non-phenolic alcohols with mainly aryl skeletons, some have } \\
\text { ethers }\end{array}$ & 1 & 39 \\
\hline Nitrogenous, mostly weakly basic, mostly aromatic & 2 & 101 \\
\hline $\begin{array}{l}\text { Furans, some tetrahydrofurans and some ethers, generally molecules with aromatic or } \\
\text { weak aromatic character }\end{array}$ & 3 & 24 \\
\hline Carboxylic acids & 4 & 13 \\
\hline Esters, mainly furanones, some ethers & 5 & 49 \\
\hline $\begin{array}{l}\text { Ketones and aldehydes, non-aromatic, includes hydroxy ketones, diketones, keto-esters } \\
\text { and Michael-acceptors, or further conjugation; including both cyclic and acyclic variants } \\
\text { of all these }\end{array}$ & 6 & 117 \\
\hline Ethers and epoxides, some acetals, no aromatics but some with unsaturation & 7 & 18 \\
\hline $\begin{array}{l}\text { Aromatic hydrocarbons, some extended conjugation and polycyclic aromatic } \\
\text { hydrocarbons (PAH), several have nitriles }\end{array}$ & 8 & 175 \\
\hline $\begin{array}{l}\text { Carbonyls with aromatic groups, includes both aldehydes and ketones, diketones, } \\
\text { hydroxy functionalised, Michael-acceptors }\end{array}$ & 9 & 42 \\
\hline Aliphatic alcohols, saturated, unsaturated, cyclic, acyclic & 10 & 51 \\
\hline Unsaturated, aliphatic hydrocarbons, cyclic and acyclic, some conjugated & 11 & 149 \\
\hline Saturated hydrocarbon, cyclic and acyclic & 12 & 20 \\
\hline Miscellaneous polar molecules: amides, sulfones, carbamates, nitriles, etc. & 13 & 20 \\
\hline
\end{tabular}

Table 4. 10-Group system.

\begin{tabular}{|c|c|c|}
\hline Chemical functionality present (10-group system) & Simple name & Number of members \\
\hline Alcohols with aromatic groups in molecule, includes phenols & Ar_OH & 39 \\
\hline Nitrogenous, basic, aliphatic and aromatic & Amine & 101 \\
\hline Ether, aliphatic and aromatic & Ether & 43 \\
\hline Carboxylic acids & Acid & 13 \\
\hline Ester, lactone, furanone, pyranone & Ester & 49 \\
\hline Carbonyls & Carbonyl & 159 \\
\hline Aromatic hydrocarbons & Ar_Hy & 162 \\
\hline Aliphatic alcohols & Al_OH & 51 \\
\hline Aliphatic hydrocarbons & Al_Hy & 169 \\
\hline Miscellaneous polar species & Misc & 32 \\
\hline
\end{tabular}

(Appendix, Figure A4). As the basis for an ordinal classification used in ordinal logistic regression analysis, compounds were classified into these three filtration selectivity groups, based on whether the analyte was higher, lower or unchanged between the two different sample types. 316 compounds were identified as being present at higher levels in the EC cigarette smoke particulate than in CR20. 389 compounds showed no significant difference, and 113 compounds were higher from the CR20 cigarette than from EC. These results confirm that the CR20 filter additive selectively, but partially, removes some compounds present in the particulate phase of mainstream cigarette smoke.

\section{Chemical classification}

One aim of the study was to identify physicochemical parameters defining compounds that CR20 removes from particulate phase mainstream smoke in addition to the volatile compounds identified in previous analysis (13). An important parameter in this exercise is chemical functionality. Compounds identified in the smoke chemistry database were therefore grouped into a number of chemical functionality clusters. A 13-cluster system (Table 3 ) was able to represent the range of chemical complexity, without oversimplification, but had too many factors to use for some methods in Minitab. A 10-group system (Table 4) was devised that, although slightly more simplistic in that it lost a few distinctions between closely related classes, was more suited to the restrictions in the software. A 7-group system (Appendix, Table A1) was explored but was found to be slightly over-simplistic, leading to marginally poorer models.

The distribution of the 13 groups within the 10-group classification are presented graphically in Figure 4 using a stacked bar chart. Hydrocarbons were combined, as were carbonyls and ethers. Aromatics with nitriles were shifted to "miscellaneous". The 7-group classification withdrew any remaining distinction between aliphatic/aromatic character, and shifted acids to the miscellaneous group.

Identification of chemical differences between CR20 and EC smoke particulates - non-parametric analysis

In the Kruskal-Wallis Test (Appendix, Table A2) aliphatic hydrocarbons were identified as having a significant association with a low median value in the CR20 particulate. Amines and aromatic alcohols were associated with the opposite tendency; a higher level in the particulate from the CR20 product. 
10 Group classification showing composition in terms of 13 group scheme

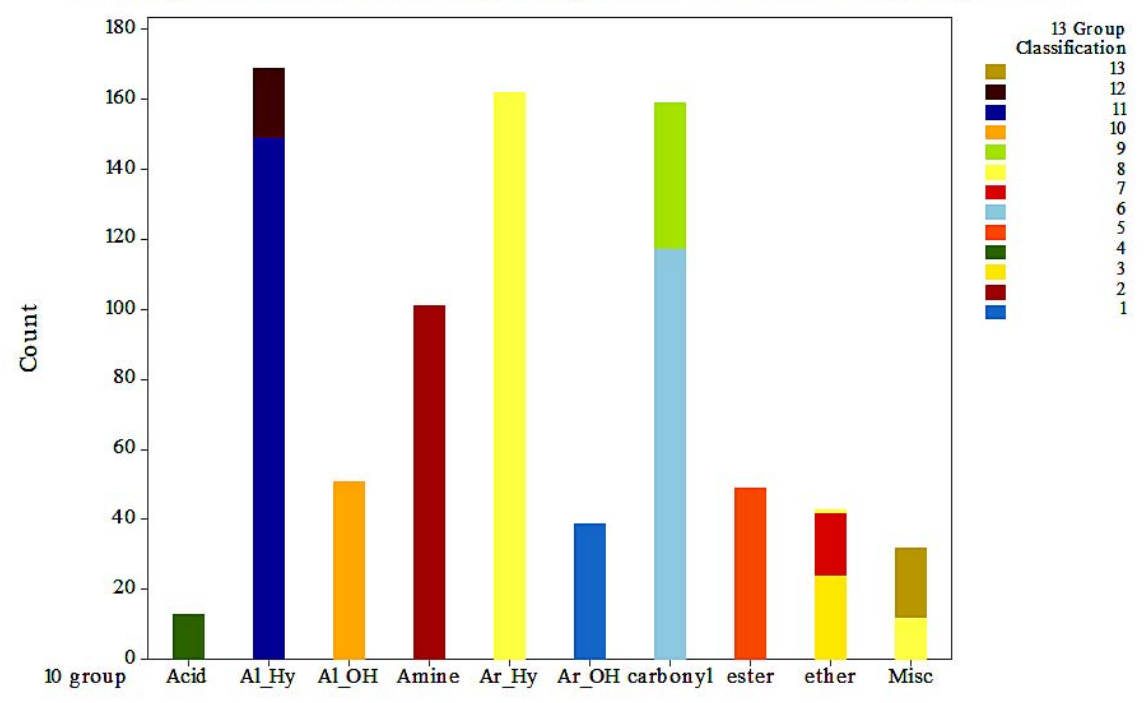

7 Group classification showing composition according to 13 group scheme

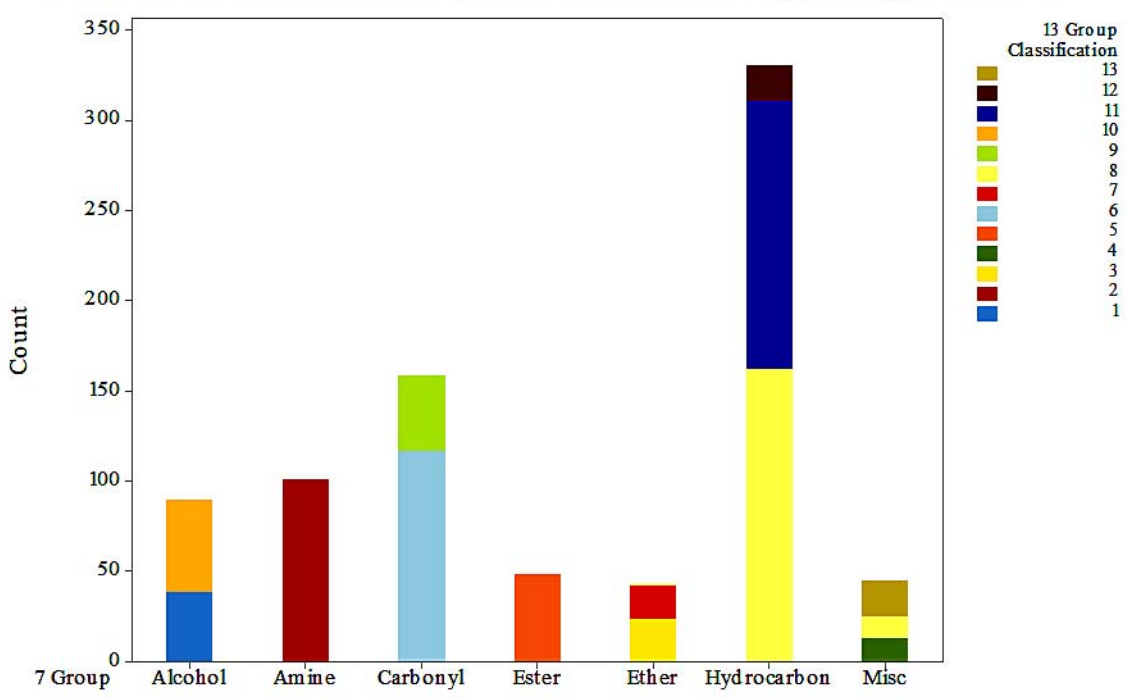

Figure 4. Simplified group classifications based on 10 groups and 7 groups in comparison to the full 13-group classification. Numbers correspond to those in Table 3.

Use of Mood's median test with the 10-group classification identified acids and aliphatic/aromatic hydrocarbons as having intervals lower than the overall grand median (0.931), and therefore having significantly lower levels in the CR20 aerosol particulate. In contrast, amines and aromatic alcohols were lower in the particulate phase of the EC cigarette (Appendix, Table A3).

These robust tests are useful to gain initial insight into the data, because they rely on few assumptions. However, neither of these tests includes covariates or interaction terms. As discussed above, it is very likely that physical factors such as volatility and polarity/lipophilicity play a role in aerosol filtration.

More sophisticated parametric models were developed, in which chromatographic retention times were used as proxy values to represent volatility $\left({ }^{1} t_{R}\right)$ and polarity $\left({ }^{2} t_{R}\right)$. We also examined the estimated water/octanol partition coefficient $(\mathrm{x} \log \mathrm{P})$ for each structure, as a proxy for lipophilicity. These continuous variables were used as covariates in the parametric models described below.

\section{Physicochemical differences between CR20 and EC smoke} particulates - parametric models

The ordinal logistic regression model provided an acceptable fit to the data, according to the goodness-of-fit tests. Both tests gave $\mathrm{P}$ values above 0.05 , supporting the null hypothesis that the data fit the model. The level of concordance between observed and predicted classifications was $87.1 \%$, leading to a Somers' D statistic of 0.74 . Kendall's tau-a shows a positive correlation of 0.45 .

The influence of the parameters in the model is given by their proportional odds ratios. For a one-unit increase in dichotomous predictor, i.e., going from 0 to 1 , the odds of 


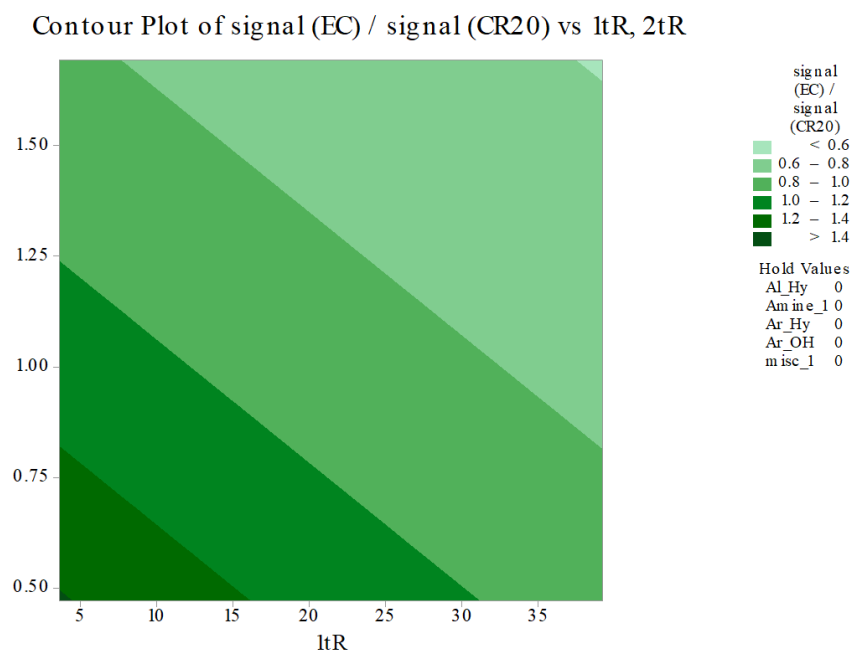

Figure 5. Contour plot arising from the linear regression analysis.

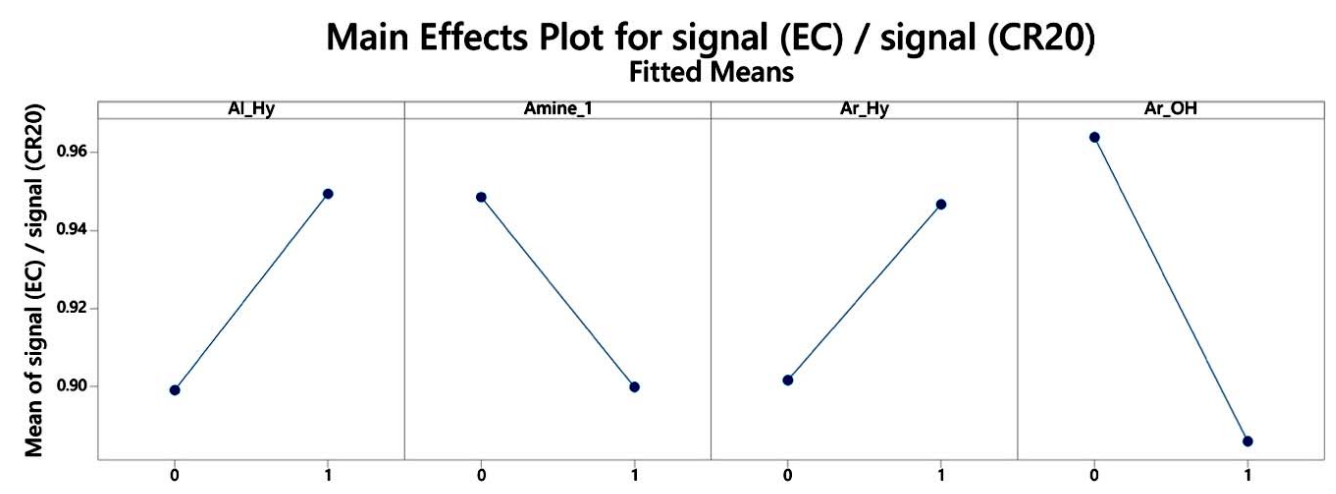

Figure 6. Summary of the chemical group directional differences between CR20 and EC cigarette particulate phase smoke samples.

moving up the scale of the response are increased by the value of the coefficient for that predictor, if all other variables in the model remain unchanged.

The same applies to the continuous predictors (the covariates); a one-unit increase in covariate brings the indicated change in odds. The covariates were not standardised, so their scales need to be considered: ${ }^{1} t_{R}$ has a max value of around $40 \mathrm{~min}$ and ${ }^{2} \mathrm{t}_{\mathrm{R}}$ has a max value around $1.8 \mathrm{~s}$.

The covariates both had negative coefficients (Appendix, Table A4), indicating that increased retention time was associated with an elevation of levels of chemicals in the CR20 particulate phase compared to the EC cigarette. The categorical amine and aromatic alcohol descriptors both had negative coefficients, with the same interpretation. The coefficients for aliphatic and aromatic hydrocarbons both had positive coefficients, indicating that the presence of these factors was linked to a reduction of the chemicals in the CR20 particulate phase compared to the EC cigarette. These trends for chemical classes agree with findings from the non-parametric tests described above. However, inclusion of covariate terms for volatility and polarity means the findings are less susceptible to con- founding interactions between chemical class and physical parameters.

A linear regression model (Appendix, Table A5) explained less than half of the variation in the response variable, but the residuals showed curvature in the residuals-versus-fit plot (Appendix, Figure A5) which is in breach of the approximations necessary for a general linear model. This was improved slightly by using a BoxCox transformation, but still raised doubts over the validity of the model coefficients. However, the lack-offit term was not significant in the model, and the directional sign of the coefficients had some credence when compared to other models of the data, so the main effects and response contour plot gave some insight.

The contour plot in Figure 5 shows that generally the higher the compound polarity and the lower the compound volatility, the higher the proportional level of analyte in the particulate from the CR20 product. This suggests that volatile and non-polar materials are preferentially adsorbed from mainstream smoke by the CR2 0 product. The main effects plot for the categorical predictors in the model (Figure 6) summarises the directional effects from the chemical subgroups that were significant in the model. The 
aromatic and aliphatic hydrocarbons were lower in the CR20 particulate, whereas amines and aromatic alcohols were higher. The directional phenomena identified in this analysis agreed well with the other analytical methods used.

\section{DISCUSSION}

This study is, to our knowledge, the first to examine selective sorption of particulate phase compounds in cigarette smoke. Previous studies have focused predominately on removal of gas or vapour phase compounds (e.g., 9, 13). The filter absorbent used in this study, CR20, is a polystyrene material cross-linked with divinyl benzene, functionalised with surface primary amine groups. Its surface pore structure is predominantly macroporous with some large mesopores, with a broad pore size distribution of 25-900 nm centred at $105 \mathrm{~nm}$, consistent with very weak physisorption properties. In contrast, it is basic, hydrophobic and offers significant chemisorption properties for vapour phase aldehydes and HCN (13).

All of the data analysis methods used in the current study identified volatile and low polarity chemicals as being proportionally lower in the particulate phase from the CR20 filtered cigarette. The agreement between the ordinal logistic regression analysis and the non-parametric methods, which rely on very few technical assumptions is encouraging, and points to patterns that can be explained by physically and chemically meaningful phenomena. For example, the selective interactions between CR20 and aryl and aromatic hydrocarbons, and their consequent partial removal from smoke, may be due to hydrophobic (13), van der Waals and pi-pi association forces arising from the polystyrene/divinylbenzene backbone of the CR20 resin. The Moods median test analysis also identified selective reduction in abundance of acids in cigarette smoke, consistent with the basic nature of CR20 and previous findings with HCN removal (13). More generally, the primary amines of CR20 resin are strongly nucleophilic and basic, and may potentially lead to amide formation or other reaction modes, including something as simple as salt formation.

The opposite trend was seen for amines, and aromatic hydroxylated compounds. These latter two groups appear to be higher in the particulate phase of the CR20 product. The trend for amino compounds may be due to the CR20 acting as a $\mathrm{pH}$ modifier and converting involatile amine salts in smoke to volatile unprotonated forms. This would result in increases of these species in the gas phase. The reason for lack of binding of aromatic hydroxylated species, however, is unclear. Plasticized cellulose acetate filters of the type used in this study have been shown to possess strong selective filtration properties for phenols (40), and potentially the presence of CR20 in the cavity may have interfered with this mechanism producing the observed effect with aromatic hydroxylated species.

These data are from the analysis of the particulate phase of cigarette smoke, the phase of total aerosol containing the less volatile components. In principle, the particulate-phase matter can only encounter the filter by impaction (filtration), which is chemically indiscriminate. However, the current study employed headspace sampling of the particulate phase, which captured only compounds possessing some degree of volatility. The distinction between particulate phase and gas phase is therefore overly simplistic and not clear-cut. Semi-volatile species were found in both particulate and gaseous phases and it is not meaningful to draw an absolute distinction between the two phases of smoke. As an illustrative example, water and formaldehyde are both known to be measurable in the particulate phase, although they are both very volatile in fresh smoke. Moreover, the tendency for more volatile particulate phase compounds to be selectively removed by CR20 further demonstrates the mobility of some particulate phase compounds, and the importance of vapour diffusion in driving selective removal of cigarette smoke compounds. Our study demonstrates the power of hyphenated analysis techniques such as GC $\times$ GC-TOFMS in aerosol research. However, such techniques require time-consuming analysis due to the large volumes of data obtained using nontargeted comprehensive screening. We demonstrated the utility of chemometric approaches in interpreting the data generated by these techniques, but it is also possible to identify opportunities for improvement. For example, although the purity of the GC $\times$ GC-TOFMS spectra was generally high, leading to good quality library matches, a number of peaks remained unassigned because they were not present among the MS libraries that were used. Such a situation is not uncommon (41); the acquisition of accurate mass data would be of significant value and should increase the frequency of peak identification. We used cheminformatic methods to classify the chemical hits into discrete groups for onward analysis. This is a novel approach in the field of smoke chemistry and offers advantages of analytical simplicity and interpretability. The classification techniques are also tolerant of trivial MS mis-assignments such as incorrect isomer or chain length identification, because they are unlikely to change group assignment. However, as with all analytical approaches, the quality of the output will always be dictated by the quality of the original dataset. A future development would be to use more sophisticated statistical tools, for example artificial neural network quantitative structure-property relationship (QSPR) to model the relationship between chemical fingerprints and filtration behavior.

\section{CONCLUSIONS}

Headspace solid-phase microextraction, coupled with GC $\times$ GC-TOFMS has been applied to the analysis of mainstream cigarette smoke particulate matter from two types of cigarette differing only in filter construction, in which one cigarette contained $60 \pm 1 \mathrm{mg}$ of CR2 0 resin in the filter cavity, while for the second cigarette, the cavity was empty.

The GC $\times$ GC-TOFMS technique (25) identified 429 compounds that differed significantly between mainstream smoke particulate phase from the two types of cigarette, thereby verifying this approach. 316 compounds were identified as being present at higher levels in the empty cavity cigarette than in CR20 and 113 compounds were higher in the smoke of the CR20 cigarette than from EC. 389 compounds showed no significant difference between the cigarettes.

CR20 was previously evaluated for its capacity to remove six aldehydes, HCN, "tar", nicotine, and CO (13). Its extensive and specific surface functionality were found to make it a good candidate for the selective chemisorption of aldehydes and HCN in cigarette smoke. The present study 
has shown that CR20 resin also partially removes more volatile and less polar compounds from the particulate phase of cigarette smoke, and some acids. In contrast, amines and aromatic hydroxylated species were increased in the smoke of CR20 cigarettes relative to empty cavity cigarettes.

Our findings demonstrate that high resolution $\mathrm{GC} \times \mathrm{GC}$ combined with mass spectrometry and chemometric approaches are a powerful tool with which to deconvolute complex combustion aerosols and to identify changes in their chemical composition resulting from modifications to cigarette designs.

\section{REFERENCES}

1. Rodgman, A. and T.S. Perfetti: The Chemical Components of Tobacco and Tobacco Smoke; $2^{\text {nd }}$ Edition, CRC Press, Boca Raton, FL, USA, 2013. ISBN 9781466515482

2. International Agency for Research Center (IARC): Tobacco Smoke and Involuntary Smoking; IARC Monographs on the Evaluation of Carcinogenic Risks to Humans Volume 83; IARC, Lyon, France, 2004.

3. International Agency for Research Center (IARC): Personal Habits and Indoor Combustions; IARC Monographs on the Evaluation of Carcinogenic Risks to Humans, Volume 100E, IARC, Lyon, France, 2012. ISBN-13: 978-9283213222

4. Fowles, J. and E. Dybing: Application of Toxicological Risk Assessment Principles to the Chemical Constituents of Cigarette Smoke; Tob. Control 12 (2003) 424-430. DOI: $10.1136 /$ tc. 12.4 .424

5. Hoffmann, D., I. Hoffmann, and K. El-Bayoumy: The Less Harmful Cigarette: A Controversial Issue. A Tribute to Ernst L. Wynder; Chem. Res. Toxicol. 14 (2001) 767-790. DOI: 10.1021/tx000260u

6. Institute of Medicine, Committee to Assess the Science Base for Tobacco Harm Reduction: Clearing the Smoke: Assessing the Science Base for Tobacco Harm Reduction; edited by K. Stratton, P. Shetty, R. Wallace, and S. Bondurant, National Academies Press, Washington, DC, USA, 2001. ISBN-10: 0-309-07282-4

7. Rouquerol, F., J. Rouquerol, and K. Sing: Adsorption by Powders and Porous Solids; Academic Press, London, UK, 1999. ISBN 978-0-12-598920-6

8. Branton, P. and R.H. Bradley: Activated Carbons for the Adsorption of Vapours from Cigarette Smoke; Adsorpt. Sci. Technol. 28 (2010) 3-21.

DOI: 10.1260/0263-6174.28.1.3

9. Branton, P., K. McAdam, M. Duke, C. Liu, M. Curle, M. Mola, C. Proctor, and R. Bradley: Use of Classical Adsorption Theory to Understand the Dynamic Filtration of Volatile Toxicants in Cigarette Smoke by Active Carbons; Adsorpt. Sci. Technol. 29 (2011).

DOI: 10.1260/0263-6174.29.2.117.

10. Branton, P.J., A.-H. Lu, and F. Schüth: The Effect of Carbon Pore Structure on the Adsorption of Cigarette Smoke Vapour Phase Compounds; Carbon 47 (2009) 1005-1011. DOI: 10.1016/j.carbon.2008.12.003

11. Reucroft, P.J. and C.T. Chiou: Adsorption of Cyanogens Chloride and Hydrogen Cyanide by Activated and Impregnated Carbons; Carbon 15 (1977) 285-290. DOI: 10.1016/0008-6223(77)90031-8

12. Barnes, P.A., M.J. Chinn, E.A. Dawson, and P.R.
Norman: Preparation, Characterisation and Application of Metal-Doped Carbons for Hydrogen Cyanide Removal; Adsorpt. Sci. Technol. 20 (2002) 817-833. DOI: $10.1260 / 02636170260555750$

13. Branton, P.J., K.G. McAdam, D.B. Winter, C. Liu, M.G. Duke, and C.J. Proctor: Reduction of Aldehydes and Hydrogen Cyanide Yields in Mainstream Cigarette Smoke Using an Amine Functionalised Ion Exchange Resin: Chem. Cent. J. 5 (2011) 15.

DOI: $10.1186 / 1752-153 \mathrm{X}-5-15$

14. Charles, S.M., S.A. Batterman, and C. Jia: Composition and Emissions of VOCs in Main- and Side-Stream Smoke of Research Cigarettes; Atmos. Environ. 41 (2007) 5371-5384.

DOI: 10.1016/j.atmosenv.2007.02.020

15. Charles, S.M., C. Jia, S.A. Batterman, and C. Godwin: VOC and Particulate Emissions from Commercial Cigarettes: Analysis of 2,5-DMF as an ETS Tracer; Environ. Sci. Technol. 42 (2008) 1324-1331. DOI: $10.1021 / \mathrm{es} 072062 \mathrm{~W}$

16. Ye, Q.: Development of Solid-Phase Microextraction Followed by Gas Chromatography-Mass Spectrometry for Rapid Analysis of Volatile Organic Chemicals in Mainstream Cigarette Smoke; J. Chromatogr. A 1213 (2008) 239-244. DOI: 10.1016/j.chroma.2008.10.063

17. Polzin, G.M., R.E. Kosa-Maines, D.L. Ashley, and C.H. Watson: Analysis of Volatile Organic Compounds in Mainstream Cigarette Smoke; Environ. Sci. Technol. 41 (2007) 1297-1302. DOI: 10.1021/es0606091

18. Phillips, J.B. and J. Beens: Comprehensive Two-Dimensional Gas Chromatography: A Hyphenated Method with Strong Coupling Between the Two Dimensions; J. Chromatogr. A 856 (1999) 331-347.

DOI: 10.1016/S0021-9673(99)00815-8

19. Dallüge, J., M. van Rijn, J. Beens, R.J.J. Vreuls, U.A.T. Brinkman: Comprehensive Two-Dimensional Gas Chromatography with Time-of-Flight Mass Spectrometric Detection Applied to the Determination of Pesticides in Food Extracts; J. Chromatogr. A 965 (2002a) 207-217. DOI: 10.1016/S0021-9673(01)01324-3

20. Dallüge, J., L.L.P. van Stee, X. Xu, J. Williams, J. Beens, R.J.J. Vreuls, and U.A.T. Brinkman: Unravelling the Composition of Very Complex Mixtures by GC $\times$ GC TOFMS Cigarette Smoke; J. Chromatogr. A 974 (2002b) 169-184.

DOI: 10.1016/S0021-9673(02)01384-5

21. Lu, X., J. Cai, H. Kong, M. Wu, R. Hua, M. Zhao, J. Liu, and G. Xu: Analysis of Cigarette Smoke Condensates by Comprehensive Two-Dimensional Gas Chromatography / Time-of-Flight Mass Spectrometry. Part I: Acidic Fraction; Anal. Chem. 75 (2003) 4441-4451. DOI: $10.1021 / \mathrm{ac} 0264224$

22. Lu, X., M. Zhao, H. Kong, J. Cai, J. Wu, M. Wu, R. Hua, J. Liu, and G. Xu: Characterization of Cigarette Smoke Condensates by Comprehensive Two-Dimensional Gas Chromatography / Time-of-Flight Mass Spectrometry (GC $\times$ GC/TOFMS). Part 2: Basic Fraction; J. Sep. Sci. 27 (2004) 101-109. DOI: $10.1002 /$ jssc.200301659

23. Lu, X., M. Zhao, H. Kong, J. Cai, J. Wu, M. Wu, R. Hua, J. Liu, and G. Xu: Characterization of Complex Hydrocarbons in Cigarette Smoke Condensate by Gas Chromatography-Mass Spectrometry and Comprehensive Two-Dimensional Gas Chromatography-Time-ofFlight Mass Spectrometry; J. Chromatogr. A 1043 
(2004) 265-273. DOI: 10.1016/j.chroma.2004.05.089

24. Brokl, M., L. Bishop, C.G. Wright, C. Liu, K.G. McAdam, and J.-F. Focant: Analysis of Mainstream Tobacco Smoke Particulate Phase Using Comprehensive Two-Dimensional Gas Chromatography Time-ofFlight Mass Spectrometry; J. Sep. Sci. 36 (2013) 1037-1044. DOI: 10.1002/jssc.201200812

25. Brokl, M., L. Bishop, C.G. Wright, C. Liu, K.G. McAdam, and J.-F. Focant: Multivariate Analysis of Mainstream Tobacco Smoke Particulate Phase by Headspace Solid-Phase Micro Extraction Coupled with Comprehensive Two-Dimensional Gas Chromatography-Time-of-Flight Mass Spectrometry; J. Chromatogr. A 1370 (2014) 216-229.

DOI: $10.1016 /$ j.chroma.2014.10.057

26. Arthur, C.L. and J. Pawliszyn: Solid Phase Microextraction with Thermal Desorption Using Fused Silica Optical Fibers; Anal. Chem. 62 (1990) 2145-2148. DOI: $10.1021 / \mathrm{ac} 00218 \mathrm{a} 019$

27. Clark, T.J. and J.E. Bunch: Quantitative Determination of Phenols in Mainstream Smoke with Solid-Phase Microextraction-Gas Chromatography - Selected Ion Monitoring Mass Spectrometry; J. Chromatogr. Sci. 34 (1996) 272-275. DOI: 10.1093/chromsci/34.6.272

28. Clark, T.J. and J.E. Bunch: Qualitative and Quantitative Analysis of Flavor Additives on Tobacco Products Using SPME-GC-Mass Spectroscopy; J. Agric. Food Chem. 45 (1997) 844-849. DOI: 10.1021/jf960522r

29. Stanfill, S.B. and D.L. Ashley: Solid Phase Microextraction of Alkenylbenzenes and Other FlavorRelated Compounds from Tobacco for Analysis by Selected Ion Monitoring Gas Chromatography-Mass Spectrometry; J. Chromatogr. A 858 (1999) 79-89. DOI: 10.1016/S0021-9673(99)00796-7

30. Merckel, C., F. Pragst, A. Ratzinger, B. Aebi, W. Bernhard, and F. Sporkert: Application of Headspace Solid Phase Microextraction to Qualitative and Quantitative Analysis of Tobacco Additives in Cigarettes; J. Chromatogr. A 1116 (2006) 10-19.

DOI: 10.1016/j.chroma.2006.03.010

31. Yang, S.S., C.B. Huang, and I. Smetena: Optimization of Headspace Sampling Using Solid-Phase Microextraction for Volatile Components in Tobacco; J. Chromatogr. A 942 (2002) 33-39. DOI: $10.1016 / \mathrm{S} 0021-9673(01) 01376-0$

32. Yang, S.S. and I. Smetena: Determination of Tobacco Alkaloids Using Solid Phase Microextraction and GCNPD; Chromatographia 47 (1998) 443-448. DOI: $10.1007 / \mathrm{BF} 02466477$

33. Watson, C.H. and D.L. Ashley: Quantitative Analysis of Acetates in Cigarette Tobacco Using Solid-Phase Microextraction and Gas Chromatography-Mass Spectrometry; J. Chromatogr. Sci. 38 (2000) 137-144. DOI: $10.1093 / \mathrm{chromsci} / 38.4 .137$.

34. Lin, H., Q. Ye, C. Deng, and X. Zhang: Field Analysis of Acetaldehyde in Mainstream Tobacco Smoke Using
Solid-Phase Microextraction and a Portable Gas Chromatograph; J. Chromatogr. A 1198-1199 (2008) 34-37. DOI: 10.1016/j.chroma.2008.05.050

35. Watson, C.H., J.S. Trommel, and D.L. Ashley: SolidPhase Microextraction-Based Approach to Determine Free-Base Nicotine in Trapped Mainstream Cigarette Smoke Total Particulate Matter; J. Agric. Food Chem. 52 (2004) 7240-7245. DOI: 10.1021/jf049455o

36. Pierce, K.M., J.C. Hoggard, J.L. Hope, P.M. Rainey, A.N. Hoofnagle, R.M. Jack, B.W. Wright, and R.E. Synovec: Fisher Ratio Method Applied to Third-Order Separation Data to Identify Significant Chemical Components of Metabolite Extracts; Anal. Chem. 78 (2006) 5068-5075. DOI: 10.1021/ac0602625

37. International Organization for Standardization (ISO): ISO 3308:2012-Routine Analytical Cigarette-Smoking Machine - Definitions and Standard Conditions; ISO, Geneva, Switzerland, 2012.

38. International Organization for Standardization (ISO): ISO 3402:1999 - Tobacco and Tobacco Products Atmosphere for Conditioning and Testing; ISO, Geneva, Switzerland, 1999.

39. Reichenbach, S.E., V. Kottapalli, M. Ni, and A. Visvanathan: Computer Language for Identifying Chemicals with Comprehensive Two-Dimensional Gas Chromatography and Mass Spectrometry; J. Chromatogr. A 1071 (2005) 263-269.

DOI: 10.1016/j.chroma.2004.08.125

40. Dittrich, D.J., R.T. Fieblekorn, M.J. Bevan, D. Rushforth, J.J. Murphy, M. Ashley, K.G. McAdam, C. Liu, and C.J. Proctor: Approaches for the Design of Reduced Toxicant Emission Cigarettes; SpringerPlus 3 (2014) 374. DOI: 10.1186/2193-1801-3-374

41. Bino, R.J., R.D. Hall, O. Fiehn, J. Kopka, K. Saito, J. Draper, B.J. Nikolau, P. Mendes, U. Roessner-Tunali, M.H. Beale, R.N. Trethewey, B.M. Lange, E.S. Wurtele, and L.W. Sumner: Potential of Metabolomics as a Functional Genomics Tool; Trends Plant Sci. 9 (2004) 418-425. DOI: 10.1016/j.tplants.2004.07.004

\section{Corresponding author:}

Kevin Gerard McAdam, Ph.D.

McAdam Scientific Ltd.

50 Leigh $R d$

Eastleigh

SO50 9DT

$U K$

E-mail:kevin@mcadamscience.com 


\section{Appendix}

Histogram of Mean ltR

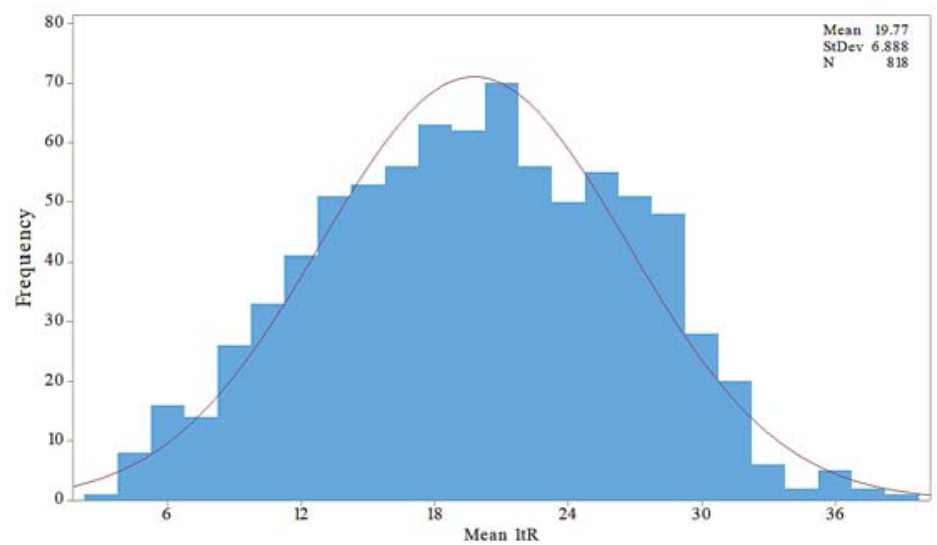

Appendix Figure A1a. Distribution of ${ }^{1} t_{R}$ values. Red Line is a normal distribution fit to the data.

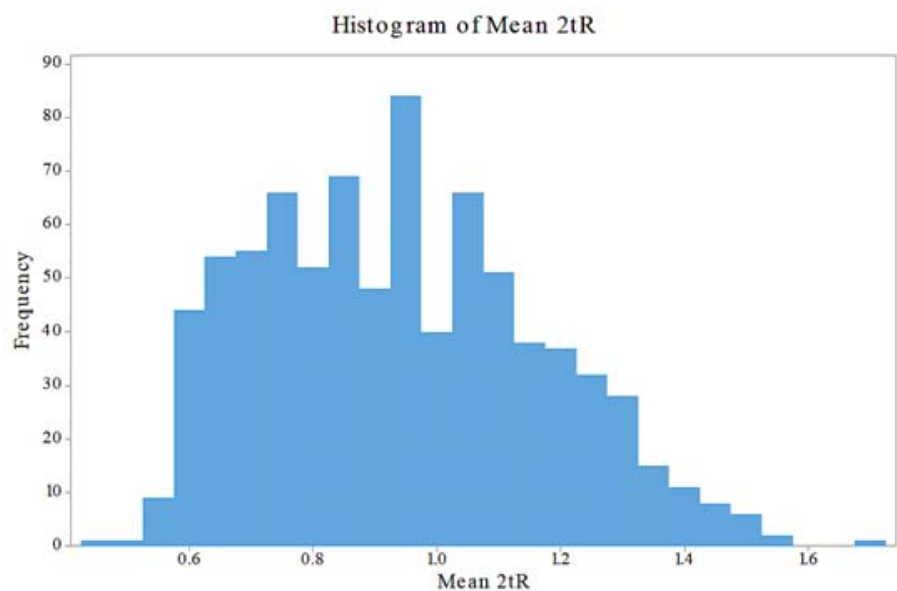

Appendix Figure A1b. Distribution of ${ }^{2} t_{R}$ values.

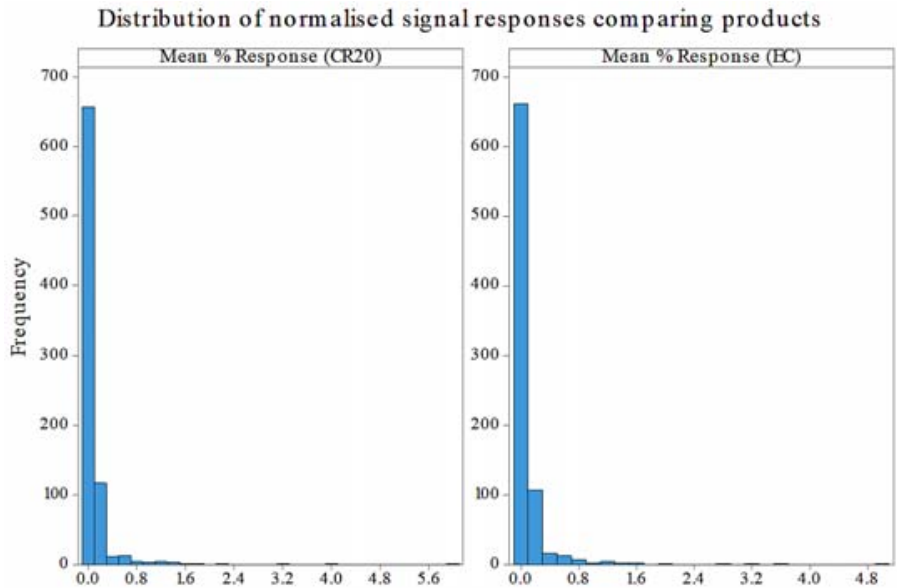

Appendix Figure A2. Distribution of normalised signal responses comparing CR20 and EC cigarettes. 


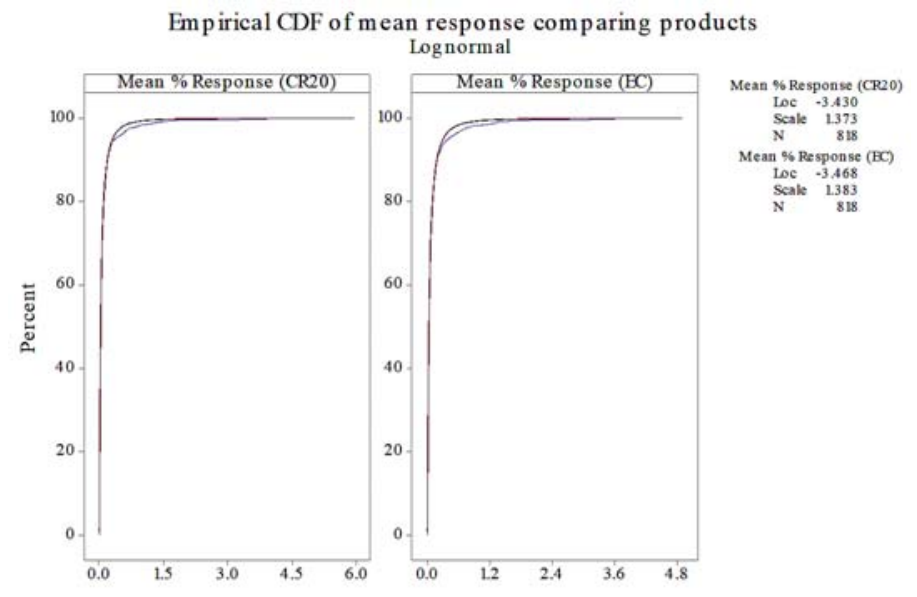

Appendix Figure A3. Empirical CDF plots of the mean response for the two products.

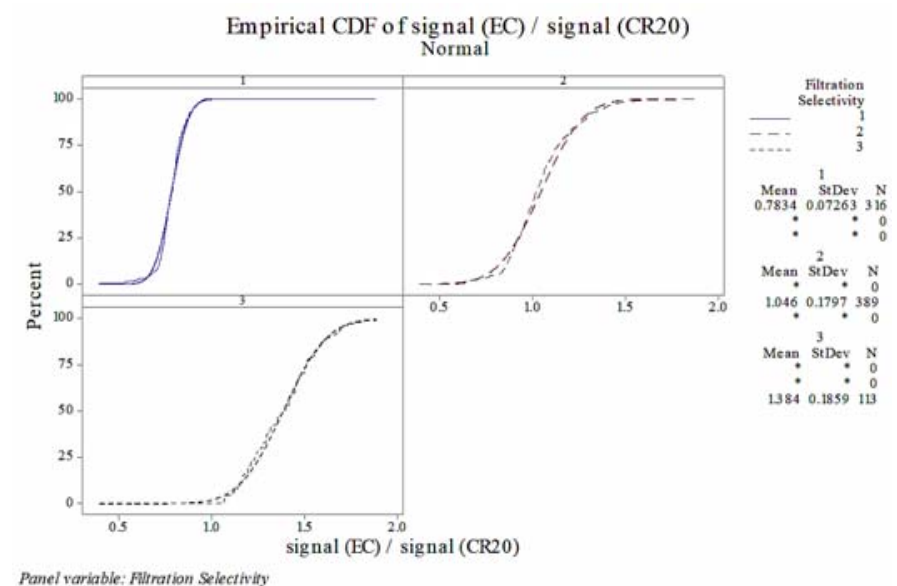

Appendix Figure A4. Normal distribution of the smoke component ratios from the two cigarettes.

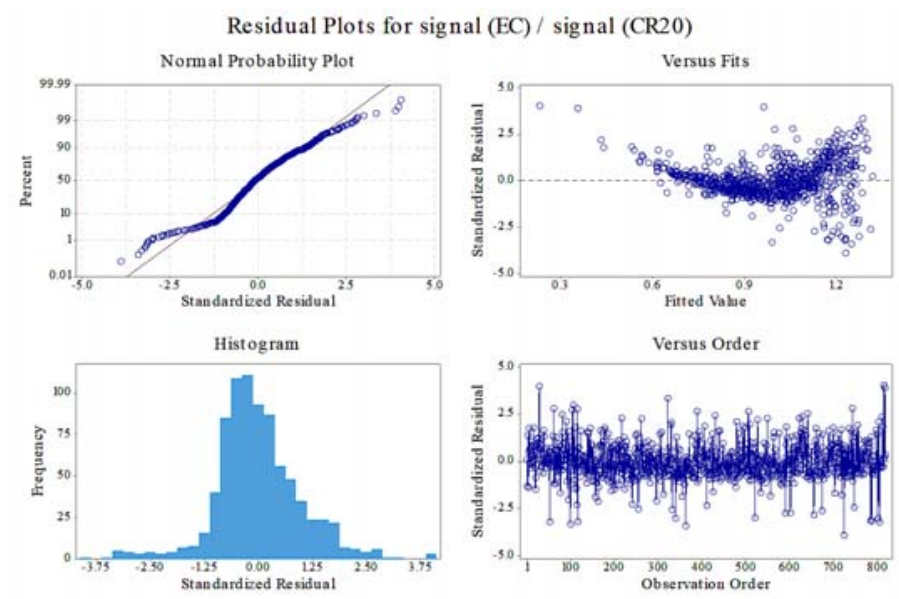

Appendix Figure A5. Residuals versus fit plot for the linear regression analysis model. 
Appendix Table A1. 7-Group system.

\begin{tabular}{|c|c|c|}
\hline Functionality present (7-group system) & Simple name & Number of members \\
\hline Alcohols: aryl and aliphatic & Alcohol & 90 \\
\hline Nitrogenous: basic, aliphatic and aromatic & Amine & 101 \\
\hline Ether, aliphatic and aromatic & Ether & 159 \\
\hline Ester: lactone, furanone, pyranone, aryl and aliphatic & Ester & 49 \\
\hline Carbonyl: aryl and aliphatic & Carbonyl & 43 \\
\hline Hydrocarbon: aryl and aliphatic, unsaturated and saturated & Hydrocarbon & 331 \\
\hline Misc. polar including acids & Misc. polar & 45 \\
\hline
\end{tabular}

Appendix Table A2. Kruskal-Wallis Test: signal (EC) / signal (CR20) versus 10-group classification factors.

a) 10-Group classification model

\begin{tabular}{|c|c|c|c|c|}
\hline Classification & $\mathrm{N}$ & Median & Ave rank & Z \\
\hline Acid & 13 & 1.0488 & 530.2 & 1.86 \\
\hline Al_Hy & 169 & 1.0622 & 510.6 & 6.24 \\
\hline Al_OH & 51 & 0.9435 & 414.8 & 0.17 \\
\hline Amine & 101 & 0.8262 & 303.6 & -4.81 \\
\hline $\mathrm{Ar} \_\mathrm{Hy}$ & 162 & 0.9778 & 441.3 & 1.92 \\
\hline Ar_OH & 39 & 0.8180 & 258.9 & -4.08 \\
\hline Carb & 159 & 0.9240 & 389.1 & -1.22 \\
\hline Esth & 49 & 0.8456 & 350.8 & -1.79 \\
\hline Ethr & 43 & 0.9406 & 406.1 & -0.10 \\
\hline Misc & 32 & 0.8974 & 370.9 & -0.94 \\
\hline Overall & 818 & & 409.5 & \\
\hline
\end{tabular}

b) Summary statistics

\begin{tabular}{l|c|c|c}
\hline & $\mathrm{H}$ & $\mathrm{DF}$ & $\mathrm{P}$ \\
\hline Model output & 78.51 & 9 & 0.000 \\
Adjusted for ties & 78.51 & 9 & 0.000 \\
\hline
\end{tabular}

Appendix Table A3. Mood Median Test: signal (EC) / signal (CR20) versus 10-group classification factors.

a) Mood median test for signal (EC) / signal (CR20)

\begin{tabular}{ll}
\hline Chi-Square & 59.80 \\
DF & 9 \\
P & 0.000 \\
Overall median & 0.931 \\
\hline
\end{tabular}


Appendix Table A3. Mood Median Test: signal (EC) / signal (CR20) versus 10-group classification factors. Continued.

b) 10-Group classification model

\begin{tabular}{l|c|c|c|c}
\hline Classification & $\mathrm{N} \leq$ & $\mathrm{N}>$ & Median & Q3-Q1 \\
\hline Acid & 2 & 11 & 1.049 & 0.318 \\
Al_Hy & 65 & 104 & 1.062 & 0.573 \\
Al_OH & 25 & 26 & 0.944 & 0.260 \\
Amine & 71 & 30 & 0.826 & 0.259 \\
Ar_Hy & 65 & 97 & 0.978 & 0.390 \\
Ar_OH & 33 & 6 & 0.818 & 0.127 \\
Carb & 82 & 77 & 0.924 & 0.306 \\
Esth & 29 & 20 & 0.846 & 0.247 \\
Ethr & 19 & 24 & 0.941 & 0.371 \\
Misc & 18 & 14 & 0.897 & 0.293 \\
\hline
\end{tabular}

Appendix Table A4. Ordinal logistic regression (Minitab).

a) Link Function: Logit

i) Response Information

\begin{tabular}{lll}
\hline Variable & Value & Count \\
\hline Filtration Selectivity & 3 & 113 \\
& 2 & 389 \\
& 1 & 316 \\
Total & & 818 \\
\hline
\end{tabular}

ii) Factor Information

\begin{tabular}{lll}
\hline Factor & Levels & Values \\
\hline Ar_OH & 2 & 0,1 \\
Ar_Hy & 2 & 0,1 \\
Amine & 2 & 0,1 \\
Al_Hy & 2 & 0,1 \\
\hline
\end{tabular}

b) Logistic Regression Table

\begin{tabular}{l|c|c|c|c|c|c|c}
\hline Predictor & Coef & SE Coef & $Z$ & \multirow{2}{*}{ P } & Odds ratio & \multicolumn{2}{|c}{$95 \% \mathrm{Cl}$} \\
\hline Const(1) & 5.04387 & 0.464802 & 10.85 & 0.000 & & & \\
Const(2) & 8.71254 & 0.551398 & 15.80 & 0.000 & & & \\
Mean $^{1} t_{R}$ & -0.135629 & 0.0132510 & -10.24 & 0.000 & 0.87 & 0.85 & 0.90 \\
Meann $^{2} t_{R}$ & -5.66062 & 0.478954 & -11.82 & 0.000 & 0.00 & 0.00 & 0.01 \\
Ar_OH 1 & -1.54180 & 0.434239 & -3.55 & 0.000 & 0.21 & 0.09 & 0.50 \\
Ar_Hy 1 & 0.462206 & 0.213196 & 2.17 & 0.030 & 1.59 & 1.05 & 2.41 \\
Amine 1 & -0.706757 & 0.270786 & -2.61 & 0.009 & 0.49 & 0.29 & 0.84 \\
Al_Hy 1 & 0.515430 & 0.233111 & 2.21 & 0.027 & 1.67 & 1.06 & 2.64 \\
\hline
\end{tabular}

Log-Likelihood $=-572.475$

c) Test that all slopes are zero

\begin{tabular}{ll}
\hline $\mathrm{G}$ & 481.794 \\
$\mathrm{DF}$ & 6 \\
P-Value & 0.000 \\
\hline
\end{tabular}


Appendix Table A4. Ordinal logistic regression (Minitab). Continued.

d) Goodness-of-Fit Tests

\begin{tabular}{lcccc}
\hline Method & Chi-Square & DF & P \\
\hline Pearson & 1638.82 & 1628 & 0.420 \\
Deviance & 1144.95 & 1628 & 1.000 \\
\hline
\end{tabular}

e) Measures of association between the response variable and predicted probabilities

\begin{tabular}{l|r|r|c|c}
\hline Pairs & Number & Percent & Summary & Measures \\
\hline Concordant & 176491 & 87.1 & Somers' D & 0.74 \\
Discordant & 25766 & 12.7 & Goodman-Kruskal Gamma & 0.75 \\
Ties & 332 & 0.2 & Kendall's Tau-a & 0.45 \\
Total & 202589 & 100.0 & & \\
\hline
\end{tabular}

Appendix Table A5. Linear regression analysis: signal (EC)/signal (CR20) versus MeanRT1, MeanRT2, Al_Hy, Amine_1, Ar_Hy, Ar_OH.

a) Box-Cox transformation

\begin{tabular}{ll}
\hline Rounded $\lambda$ & -0.5 \\
Estimated $\lambda$ & -0.41346 \\
$95 \%$ Cl for $\lambda$ & $(-0.627960,-0.196960)$ \\
\hline
\end{tabular}

b) Analysis of variance for transformed response

\begin{tabular}{lrrrrrr}
\hline Source & DF & Adj SS & Adj MS & F-Value & P-Value \\
\hline Regression & 6 & 4.7498 & 0.79164 & 91.72 & 0.000 \\
Mean $^{1} t_{R}$ & 1 & 1.1622 & 1.16224 & 134.66 & 0.000 \\
Mean $^{2} t_{R}$ & 1 & 1.2409 & 1.24086 & 143.77 & 0.000 \\
Al_Hy & 1 & 0.0676 & 0.06755 & 7.83 & 0.005 \\
Amine_1 & 1 & 0.0583 & 0.05827 & 6.75 & 0.010 \\
Ar_Hy & 1 & 0.0648 & 0.06478 & 7.51 & 0.006 \\
Ar_OH & 1 & 0.0669 & 0.06693 & 7.75 & 0.005 \\
Error & 811 & 6.9998 & 0.00863 & & \\
Total & 817 & 11.7496 & & & \\
\hline
\end{tabular}

c) Model summary for transformed response

\begin{tabular}{lc}
\hline $\mathrm{S}$ & 0.0929035 \\
R-sq & $40.43 \%$ \\
R-sq(adj) & $39.98 \%$ \\
R-sq(pred & $39.41 \%$ \\
\hline
\end{tabular}

d) Coefficients for transformed response

\begin{tabular}{lllll|l}
\hline Term & Coef & SE Coef & T-Value & P-Value & VIF \\
\hline Constant & -0.7166 & 0.0176 & -40.61 & 0.000 & \\
Mean $^{1} t_{R}$ & -0.005953 & 0.000513 & -11.60 & 0.000 & 1.18 \\
Mean $^{2} t_{R}$ & -0.2097 & 0.0175 & -11.99 & 0.000 & 1.48 \\
Al_Hy1 & 0.0284 & 0.0101 & 2.80 & 0.005 & 1.60 \\
Amine_1 1 & -0.0274 & 0.0105 & -2.60 & 0.010 & 1.14 \\
Ar_Hy 1 & 0.02539 & 0.00927 & 2.74 & 0.006 & 1.29 \\
Ar_OH 1 & -0.0439 & 0.0158 & -2.78 & 0.005 & 1.07 \\
\hline
\end{tabular}

